\title{
Use of fractional factorial design for optimizing removal of nickel, copper, cadmium and lead by buriti modified fibers
}

\author{
D. Q. MELO ${ }^{1}$, C. B. VIDAL ${ }^{2}$, G. S.C. RAULINO ${ }^{3}$, J. T. OLIVEIRA ${ }^{1}$, R. N. P. TEIXEIRA ${ }^{3}$ E \\ R.F. NASCIMENTO ${ }^{1}$ \\ ${ }^{1}$ Universidade Federal do Ceará, Departamento de Analítica e Físico-Química \\ 2,3 Universidade Federal do Ceará, Departamento de Engenharia Hidráulica e Ambiental \\ E-mail para contato: diegodqm@gmail.com
}

RESUMO - The adsorption of copper, cadmium, lead and nickel in mono-element and multielement aqueous solutions onto buriti modified fibers was studied. The fractional factorial design $2^{4-1}$ showed that $\mathrm{pH}$, adsorbent mass, agitation rate and initial metal concentration influenced each metal adsorption differently. The kinetics and thermodynamic equilibrium parameters were obtained for all elements. The results showed that the order of mono-element adsorption for these three contaminants is $\mathrm{Ni}>\mathrm{Cd}>\mathrm{Pb}>\mathrm{Cu}$. The adsorption kinetics were fitted to the pseudo-second order model, giving linear correlation coefficients higher than 0.98. The Langmuir isotherm provided the best fit with the monoelement experimental data. In this study, the multi-element system isotherms were also obtained and a significant difference was found in the competitiveness for the site and the adsorption capacity order was $\mathrm{Ni}>\mathrm{Cu}>\mathrm{Cd}>\mathrm{Pb}$.

\section{INTRODUCTION}

Recently, a progressive increase in industrialization and urbanization has substantially enhanced the aquatic environmental pollution by the discharge of industrial effluents containing various pollutants. Among these, the toxic metals produced and consumed by various industrial sectors such as mining, textiles, painting, electroplating, refining and pesticides generate a huge volume of toxic wastewater contaminated with highly toxic metals. Some general techniques for heavy metals removal are ion exchange, nanofiltration, precipitation an activated carbon adsorption. Among the various techniques, adsorption from waste is very popular due to its low cost and simplicity (MELO, et al. 2013). Various lignocellulose-derived materials have been studied as adsorbents including cellulosic substrates, sugar cane bagasse (SOUSA et al. 2009), cashew bagasse (MOREIRA et al. 2009), coconut shell ( NETO et al. 2012). A major advantage of using natural fibers as adsorbents is the ready availability of renewable sources in nature, the low costs, the biodegradability, as well as the excellent mechanical properties. The present work focuses on removal of $\mathrm{Cd}^{2+}, \mathrm{Cu}^{2+}, \mathrm{Ni}^{2+}$ and $\mathrm{Pb}^{2+}$ ions from aqueous multi-element solutions using buriti fibers as an adsorbent. The importance of working with multi-element solutions is the simulation of industrial effluents, since most contain two or more pollutants, as desiring a more effective and versatile adsorbent. However, it is important to highlight the effect of competition for the active sites of the adsorbent, which affects the adsorption capacity and can be altered with changing and / or other parameters studied.

\section{MATERIALS AND METHODS}




\subsection{Materials}

Analytical-grade chemicals and ultrapure water (Millipore Direct Q3 Water Purification System) were used to prepare the solutions. Multi-element stock solutions of $\mathrm{Cd}^{2+,} \mathrm{Cu}^{2+,} \mathrm{Ni}^{2+}$, and $\mathrm{Pb}^{2+}\left(500 \mathrm{mg} \cdot \mathrm{L}^{-1}\right)$ were prepared with $\mathrm{Cd}\left(\mathrm{NO}_{3}\right)_{2} \cdot 4 \mathrm{H}_{2} \mathrm{O}, \mathrm{Cu}\left(\mathrm{NO}_{3}\right)_{2} \cdot 3 \mathrm{H}_{2} \mathrm{O}, \mathrm{Ni}\left(\mathrm{NO}_{3}\right)_{2} \cdot 6 \mathrm{H}_{2} \mathrm{O}$, and $\mathrm{Pb}\left(\mathrm{NO}_{3}\right)_{2}$ (Merck, São Paulo, Brazil), respectively. The acetate buffer was prepared with sodium acetate and glacial acetic acid. $\mathrm{NaOH}\left(0.10 \mathrm{~mol} . \mathrm{L}^{-1}\right)$ and $\mathrm{HCl}\left(0.10 \mathrm{~mol} . \mathrm{L}^{-1}\right)$ solutions were used for $\mathrm{pH}$ adjustments. Buriti fibers were supplied by Embrapa Tropical Agroindustry, CE, Brazil (EMBRAPA/CE).

\subsection{Batch adsorption experiments}

Batch adsorption experiments were conducted at room temperature $\left(28^{\circ} \mathrm{C}\right)$ to study the effect of solution $\mathrm{pH}(4.5-5.5)$, initial ion concentration (100-500 $\left.\mathrm{mg} \mathrm{L}^{-1}\right)$, agitation rate (100$200 \mathrm{rpm})$ and the adsorbent mass $(0.05-0.150 \mathrm{~g})$ until equilibrium was reached. The concentrations of $\mathrm{Cu}^{2+}, \mathrm{Cd}^{2+}, \mathrm{Ni}^{2}{ }^{+}$and $\mathrm{Pb}^{2+}$ were measured with an atomic absorption spectrophotometer (933 plus, GBC, Australia). The equilibrium adsorption capacity of the adsorbent was calculated with eq 1

$$
q_{e}=\frac{\left(C_{o}-C_{e}\right)}{W} V
$$

where $\mathrm{q}_{\mathrm{e}}$ is the equilibrium adsorption capacity e total equilibrium adsorption capacity ( $\mathrm{mg}$ of metal/g adsorbent), Co is the initial concentration of the metal ion in $\mathrm{mg} \cdot \mathrm{L}^{-1}, \mathrm{C}_{\mathrm{e}}$ is the equilibrium concentration of metal ion in $\mathrm{mg} \cdot \mathrm{L}^{-1}, \mathrm{~V}$ is the volume of the solution in liters, and $\mathrm{W}$ is the mass of adsorbent in grams. All of the data presented are the mean values of two results obtained in identical essays. Variation coefficients were found to be lower than $5 \%$, and the statistical analysis was carried out with Microsoft Excel software.

\subsection{Experimental Design and Statistical Analysis}

A fractional factorial design was conducted to study the influence of four factors in the multi-element ion adsorption of $\mathrm{Cu}^{2+}, \mathrm{Pb}^{2+}, \mathrm{Ni}^{2+}$ and $\mathrm{Cd}^{2+}$ using buriti fibers as adsorbent (Table 1). Buriti fibers were added to multi-element solutions $(25.0 \mathrm{~mL})$ in $50 \mathrm{~mL}$ Erlenmeyer flasks. The mixtures were mechanically stirred for $2 \mathrm{~h}$ at $28 \pm 2^{\circ} \mathrm{C}$.

Table 1 - Coded factors used in the $2^{4-1}$ fractional factorial design for studying the adsorption of $\mathrm{Cu}^{2+}, \mathrm{Pb}^{2+}, \mathrm{Ni}^{2+}$ and $\mathrm{Cd}^{2+}$ by buriti fibers

\begin{tabular}{ccccc}
\hline Code & Factor (unit) & $(-)$ & 0 & $(+)$ \\
\hline $\mathrm{A}$ & $\mathrm{pH}$ & 4.5 & 5.0 & 5.5 \\
$\mathrm{~B}$ & Adsorbent masss $(\mathrm{mg})$ & 50 & 100 & 150 \\
$\mathrm{C}$ & Agitation rate $(\mathrm{rpm})$ & 100 & 150 & 200 \\
$\mathrm{D}$ & Initial metal concentration $\left(\mathrm{mg} \mathrm{L}^{-1}\right)$ & 100 & 300 & 500 \\
\hline
\end{tabular}

A two level fractional factorial design $\left(2^{4-1}\right)$ with central point was applied to study the factors that most influence the response. The experiments were performed with four 
replications in the corner points (combinations of '-' and ' + ' levels) and eight central points. The adsorption capacity, $q_{M(I I)}$, of each metal and total adsorption capacity, $q_{t o t}$, were the responses measured. The values of $q_{M(I I)}$ were calculated using equation 1 . The total adsorption capacity, $q_{t o t}$, was calculated using the following relationship:

$$
q_{t o t}=\sum_{j=1}^{4} \frac{\left(C_{0, j}-C_{e, j}\right)}{W} V
$$

where $C_{0, j}$ is the initial metal ion concentration (given in units of $\mathrm{mg} / \mathrm{L}$ ), $C_{e, j}$ the equilibrium metal ion concentration (also given in $\mathrm{mg} / \mathrm{L}$ ), $W$ the adsorbent mass (given in units of $\mathrm{g}$ ) and $V$ the volume (given in units of $\mathrm{L}$ ).

MINITAB statistical software (version 16) was used to design and analyze the fractional factorial experiments. The results were analyzed to estimate the effects of each factor on the adsorption process. Data were reported as mean \pm standard deviation at a significance level of $p<0.05$. Pareto charts were constructed using the results of the Student's t-test. The results obtained were fit to mathematical models using analysis of variance (ANOVA).

\subsection{Adsorption kinetics}

The multi-element solution was continuously shaken at $\mathrm{pH}$ appropriate. Aliquots of the supernatant were collected at regular time intervals, up to $60 \mathrm{~min}$. Adsorption capacities were calculated by the differences between the initial and the final concentrations at any given time.

\subsection{Adsorption isotherms}

Bururi fibers were added to mono-element and multi-elements solutions in $50-\mathrm{mL}$ Erlenmeyer flasks, with metal ion concentrations in the range of $20 \mathrm{mg} . \mathrm{L}^{-1}$ to $500 \mathrm{mg} . \mathrm{L}^{-1}$, at $\mathrm{pH}$ appropriate. The data obtained for the adsorption isotherms were described according to the Langmuir (Equation 2) and Freundlich (Equation 3) models:

$$
\begin{gathered}
q_{e}=\frac{q_{\operatorname{máx}} K_{L} C_{e}}{\left(1+K_{L} C_{e}\right)} \\
q_{e}=K_{f} C_{e}^{1 / n}
\end{gathered}
$$

where: $\mathrm{C}_{\mathrm{e}}$ is the solute concentration at equilibrium $\left(\mathrm{mg} \cdot \mathrm{L}^{-1}\right), \mathrm{q}_{\mathrm{e}}$ is the amount of metal ion that is adsorbed at equilibrium (mg. $\left.\mathrm{g}^{-1}\right), \mathrm{q}_{\max }$ is the monolayer capacity of the adsorbent (mg. $\mathrm{g}^{-1}$ ), and $\mathrm{K}_{\mathrm{L}}$ is the Langmuir adsorption constant, which is related to the energy of adsorption $\left(\mathrm{L} \cdot \mathrm{mg}^{-1}\right) . \mathrm{K}_{\mathrm{f}}\left(\mathrm{L} \cdot \mathrm{mg}^{-1}\right)$ and $\mathrm{n}$ are Freundlich adsorption isotherm constants related to the saturation capacity and intensity of adsorption, respectively.

\section{RESULTS AND DISCUSSION}

\subsection{Results of the Experimental Design and Statistical Analysis}


The results obtained through the experimental design for multi-element metal ions adsorption using buriti fibers are presented at table 2. Based on the experimental data, the variables evidencing statistically significant effects were determined via t-test. The confidence degree was set at $95 \%$ (alpha $=0.05$ ) which means that variables having a confidence exceeding 95\% $(P$-value $<0.05)$ were considered to have a significant effect on the responses.

Table 2 - Column assignment for the various factors in the fractional factorial design $\left(2^{4-1}\right)$ and experimental values for multi-element metal ions adsorption

\begin{tabular}{|c|c|c|c|c|c|c|c|c|c|}
\hline \multirow[b]{2}{*}{ Run } & \multicolumn{4}{|c|}{ Coded Factors } & \multirow[b]{2}{*}{$q_{C u(I I)}$} & \multirow[b]{2}{*}{$q_{P b(I I)}$} & \multirow[b]{2}{*}{$\boldsymbol{q}_{N i(I I)}$} & \multirow[b]{2}{*}{$q_{C d(I I)}$} & \multirow[b]{2}{*}{$q_{\text {tot }}$} \\
\hline & $\mathbf{A}$ & $\mathbf{B}$ & $\mathbf{C}$ & D* & & & & & \\
\hline 1 & - & - & - & - & $5.65 \pm 1.23$ & $16.15 \pm 0.56$ & $4.48 \pm 0.84$ & $8.74 \pm 1.04$ & $35.02 \pm 2.72$ \\
\hline 2 & + & - & - & + & $26.93 \pm 0.26$ & $40.96 \pm 0.84$ & $22.14 \pm 0.53$ & $8.70 \pm 0.76$ & $98.72 \pm 1.26$ \\
\hline 3 & - & + & - & + & $9.59 \pm 0.87$ & $18.99 \pm 0.18$ & $4.63 \pm 0.51$ & $6.01 \pm 5.13$ & $39.21 \pm 5.69$ \\
\hline 4 & + & + & - & - & $8.77 \pm 0.48$ & $8.54 \pm 0.72$ & $2.19 \pm 0.53$ & $2.37 \pm 0.44$ & $21.88 \pm 1.92$ \\
\hline 5 & - & - & + & + & $4.02 \pm 0.68$ & $32.94 \pm 0.86$ & $18.48 \pm 0.91$ & $21.22 \pm 0.70$ & $76.66 \pm 1.83$ \\
\hline 6 & + & - & + & - & $9.60 \pm 0.68$ & $20.82 \pm 0.85$ & $4.76 \pm 1.29$ & $2.38 \pm 1.61$ & $37.55 \pm 1.97$ \\
\hline 7 & - & + & + & - & $3.41 \pm 0.67$ & $7.50 \pm 0.20$ & $1.91 \pm 0.28$ & $1.34 \pm 0.26$ & $14.16 \pm 1.17$ \\
\hline 8 & + & + & + & + & $20.41 \pm 0.57$ & $25.17 \pm 0.38$ & $13.53 \pm 0.30$ & $4.32 \pm 0.91$ & $63.43 \pm 0.69$ \\
\hline 9 & 0 & 0 & 0 & 0 & $5.70 \pm 0.30$ & $8.50 \pm 0.95$ & $2.71 \pm 0.82$ & $4.34 \pm 1.07$ & $21.25 \pm 1.86$ \\
\hline
\end{tabular}

* Generator: $\mathrm{I}=\mathrm{ABCD}$

The $2^{4-1}$ fractional factorial design is an example of experimental design of resolution IV. In this type of design it is possible to estimate main effects without confusion with twofactor interactions, but two-factor interaction effects are confounded with other two-factor interactions. This means that two-factor interaction effects are not precisely estimated. Instead we can estimate its contrasts. A contrast is a linear combination of two or more factor level means. The contrasts are formed according to the confounding pattern, also known as aliasing. The confounding pattern is determined by the defining relation (generator) of the model. The defining relation used in this work is $I=A B C D$. This notation is used in matricial equations and can be used to determine all the relations between factors. From the defining relation of the model one can easily see that main effects are free from aliasing with twoeffect interaction effects, but are confounded with three-factor interaction effects $(A=B C D ; B$ $=A C D ; C=A B D ; D=A B C$ ). Thus the contrasts between the main effects and the three-factor effects are $l_{A}=A+B C D ; l_{B}=B+A C D ; l_{C}=C+A B D ; l_{D}=D+A B C$. One can also prove that two-interaction effects follow the relations $A B=C D ; A C=B D ; A D=B C$. The contrasts of two-interaction effects are $l_{A B}=A B+C D ; l_{A C}=A C+B D ; l_{A D}=A D+B C$. According to Box, Hunter and Hunter (1978) the higher order interaction effects (3- and 4-factor interactions in this study) are often negligible and can be ignored. Thus, the main effects can be obtained without confusion with higher order interaction effects. The Pareto charts for $q_{C u(I I)}, q_{P b(I I)}$, $q_{N i(I I)}$, and $q_{C d(I I)}$ are presented in figure 1 . Observing figure 1 it can be seen that all main 
effects influence $q_{C u(I I)}$ and $q_{N i(I I)}$, and the only non-significant main effect for $q_{P b(I I)}$ and $q_{C d(I I)}$ is $C$ (agitation rate).
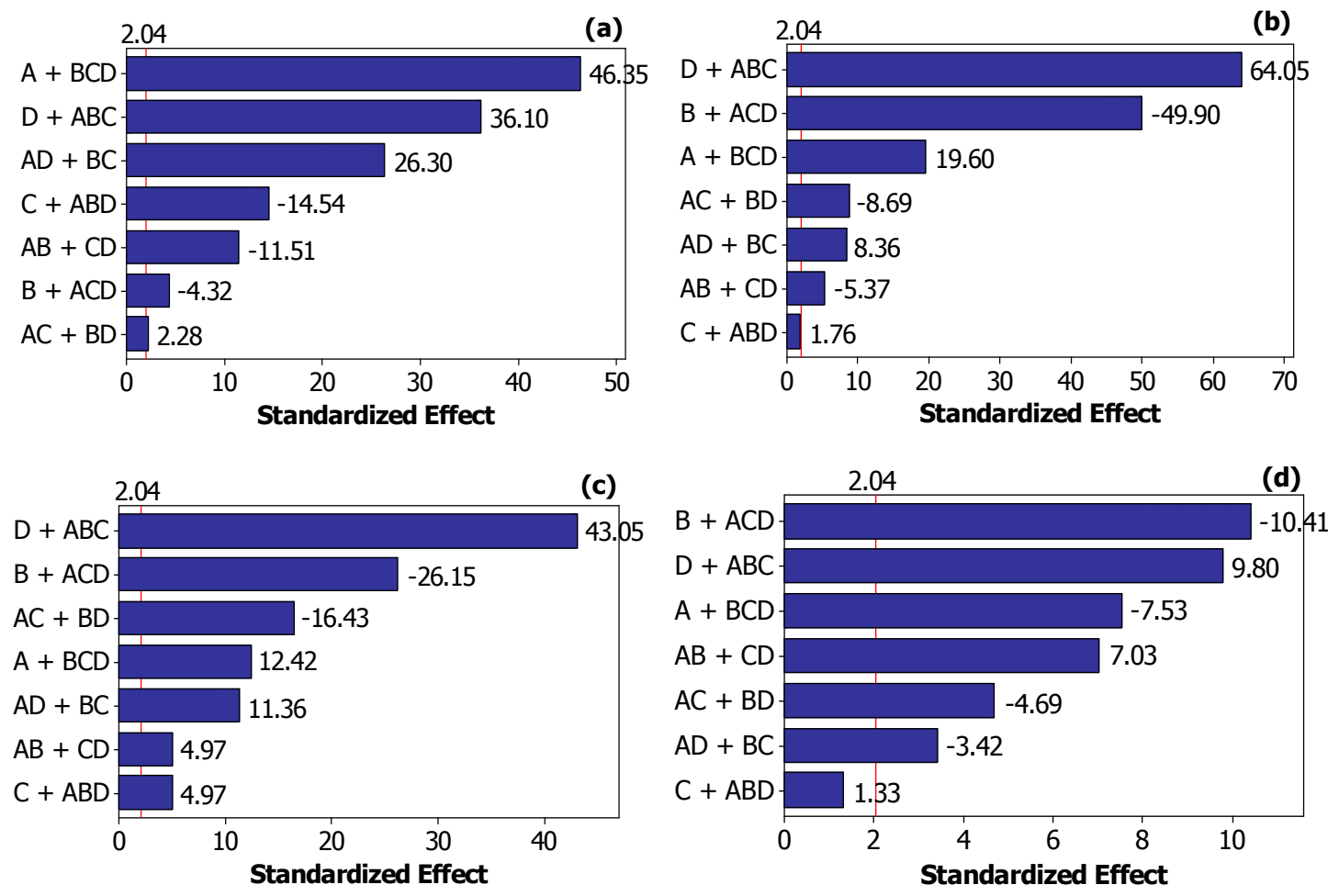

Figure 1 - Standardized Pareto charts showing main effects of experimental parameters on responses at the confidence limit of $95 \%$ for: (a) $q_{C u(I I)}$, (b) $q_{P b(I I)}$, (c) $q_{N i(I)}$, and (d) $q_{C d(I I)}$.

It is important to remember that in a multi-element system the competition effect have to be taken into account when assessing the effect of each factor on the adsorption of each metal. The overall adsorption uptake is a good way to measure the efficiency of the adsorption process in multi-element solutions. The Pareto chart for $q_{t o t}$ is presented in figure 2 . The main effects affecting the response are $D$ (initial metal concentration), $B$ (adsorbent mass) and $A(\mathrm{pH})$. Variable $\mathrm{C}$ (agitation rate) is not statistically Significant in this interval studied. This suggests that the film around the particle is overcome in the investigated range (100 to $200 \mathrm{rpm}$ ) leading to similar responses.

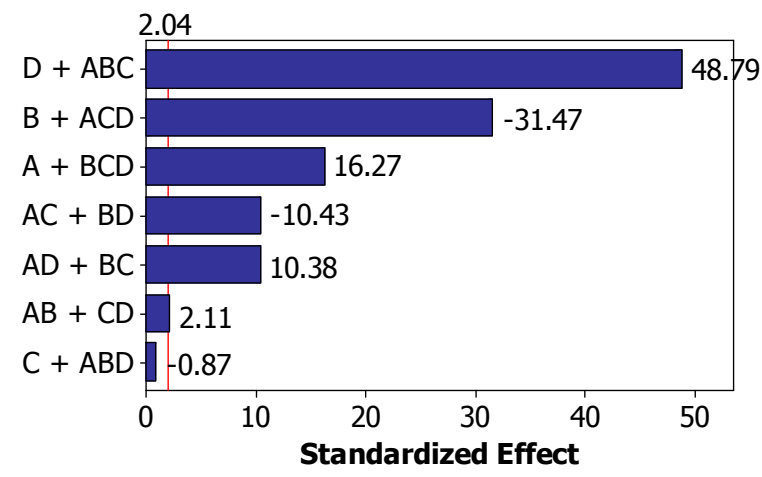


Figure 2 - Standardized Pareto charts showing main effects of experimental parameters on responses at the confidence limit of $95 \%$ for $q_{t o t}$.

The analysis of variance (ANOVA) results for $q_{C u(I)}, q_{P b(I I)}, q_{N i(I)}$, and $q_{C d(I I)}$ are shown at table 3. The ANOVA results indicate the significance of the models $(P=0.05)$ showing that there are relationships between factors and responses. The determination coefficients at $95 \%$ of confidence level were $0.9921,0.9958,0.9892$ and 0.8998 , for $q_{C u(I I)}, q_{P b(I I)}, q_{N i(I)}$, and $q_{C d(I I)}$, respectively.

Table 3 - Analysis of Variance (ANOVA) for each metal capacity adsorption

\begin{tabular}{|c|c|c|c|c|c|c|c|c|c|}
\hline & & \multicolumn{4}{|c|}{$q_{C u(I I)}$} & \multicolumn{4}{|c|}{$q_{P b(I I)}$} \\
\hline Source & DF & SS & MS & $F$ & $\boldsymbol{P}$ & SS & MS & $F$ & $P$ \\
\hline Model & 8 & 2128.15 & 266.02 & 616.87 & 0.000 & 4750.35 & 593.79 & 1151.78 & 0.000 \\
\hline A & 1 & 926.26 & 926.26 & 2147.91 & 0.000 & 197.95 & 197.95 & 383.97 & 0.000 \\
\hline$B$ & 1 & 8.04 & 8.04 & 18.64 & 0.000 & 1283.51 & 1283.51 & 2489.63 & 0.000 \\
\hline$C$ & 1 & 91.13 & 91.13 & 211.32 & 0.000 & 1.59 & 1.59 & 3.08 & 0.089 \\
\hline$D$ & 1 & 562.03 & 562.03 & 1303.30 & 0.000 & 2114.93 & 2114.93 & 4102.32 & 0.000 \\
\hline$A B$ & 1 & 57.10 & 57.10 & 132.42 & 0.000 & 14.89 & 14.89 & 28.88 & 0.000 \\
\hline$A C$ & 1 & 2.24 & 2.24 & 5.20 & 0.030 & 38.94 & 38.94 & 75.53 & 0.000 \\
\hline$A D$ & 1 & 298.28 & 298.98 & 691.69 & 0.000 & 36.01 & 36.01 & 69.86 & 0.000 \\
\hline Curvature & 1 & 183.07 & 183.07 & 424.52 & 0.000 & 1062.53 & 1062.53 & 2060.98 & 0.000 \\
\hline Pure Error & 31 & 13.37 & 0.43 & & & 15.98 & 0.52 & & \\
\hline \multicolumn{6}{|c|}{$R^{2}=0.9938, R^{2} a d j=0.9921$} & \multicolumn{4}{|c|}{$R^{2}=0.9966, R^{2} a d j=0.9958$} \\
\hline & & \multicolumn{4}{|c|}{$q_{N i(I I)}$} & \multicolumn{4}{|c|}{$q_{C d(I I)}$} \\
\hline Source & DF & SS & MS & $\boldsymbol{F}$ & $\boldsymbol{P}$ & SS & MS & $\boldsymbol{F}$ & $\boldsymbol{P}$ \\
\hline Model & 8 & 2003.40 & 250.42 & 449.57 & 0.000 & 1205.28 & 150.66 & 44.76 & 0.000 \\
\hline$A$ & 1 & 85.95 & 85.95 & 154.29 & 0.000 & 190.87 & 190.87 & 56.70 & 0.000 \\
\hline$B$ & 1 & 380.81 & 380.81 & 683.64 & 0.000 & 364.48 & 364.48 & 108.28 & 0.000 \\
\hline$C$ & 1 & 13.73 & 13.73 & 24.65 & 0.000 & 5.92 & 5.92 & 1.76 & 0.194 \\
\hline$D$ & 1 & 1032.31 & 1032.31 & 1853.22 & 0.000 & 323.05 & 323.05 & 95.97 & 0.000 \\
\hline$A B$ & 1 & 13.75 & 13.75 & 24.69 & 0.000 & 166.32 & 166.32 & 49.41 & 0.000 \\
\hline$A C$ & 1 & 150.33 & 150.33 & 269.87 & 0.000 & 74.06 & 74.06 & 22.00 & 0.000 \\
\hline$A D$ & 1 & 71.87 & 71.87 & 129.01 & 0.000 & 39.29 & 39.29 & 11.67 & 0.002 \\
\hline Curvature & 1 & 254.65 & 254.65 & 457.15 & 0.000 & 41.29 & 41.29 & 12.27 & 0.001 \\
\hline Pure Error & 31 & 17.27 & 0.56 & & & 104.35 & 3.37 & & \\
\hline
\end{tabular}

The ANOVA results for $q_{t o t}$ are shown at table 4 . The determination coefficient at $95 \%$ of confidence level was 0.9916 , which demonstrates the high correlation between observed and predicted values while the rest $(0.84 \%)$ was explained by the residues.

Table 4 - Analysis of Variance (ANOVA) for $q_{t o t}$

\begin{tabular}{cccccc}
\hline Source & Sum of squares & DF & Mean square & $\boldsymbol{F}$ & $\boldsymbol{P}$ \\
\hline Model & 27949.0 & 8 & 3493.6 & 579.49 & 0.000 \\
$A$ & 1596.8 & 1 & 1596.8 & 264.85 & 0.000 \\
$B$ & 5970.2 & 1 & 5970.2 & 990.27 & 0.000
\end{tabular}




\begin{tabular}{cccccc}
$C$ & 4.6 & 1 & 4.6 & 0.76 & 0.389 \\
$D$ & 14351.7 & 1 & 14351.7 & 2380.52 & 0.000 \\
$A B$ & 26.9 & 1 & 26.9 & 4.47 & 0.043 \\
$A C$ & 655.9 & 1 & 655.9 & 108.79 & 0.000 \\
$A D$ & 649.3 & 1 & 649.3 & 107.70 & 0.000 \\
Curvature & 4693.6 & 1 & 4693.6 & 778.53 & 0.000 \\
Pure Error & 186.9 & 31 & 6.0 & & \\
\hline \multicolumn{5}{c}{$R^{2}=0.9934, R^{2} a d j=0.9916$} \\
\end{tabular}

Table 5 shows the regression equations for the five responses analyzed in the experimental design. The term CtPt in the equations is the curvature in the model introduced by the addition of a central point. It indicates that the relationship between the variables is not linear. The fitted equations can be used to estimate the results of an adsorption experiment. The maximum value for total adsorption, $q_{t o t}$, according to the fitted model, is obtained maintaining factors $A(\mathrm{pH})$ and $D$ (initial metal concentration) at higher level $(+1)$ and factors $B$ (adsorbent mass) and $C$ (agitation rate) at lower level (-1). Following that set of factors the model indicates a total adsorption of $98.34 \mathrm{mg} \mathrm{g}^{-1}$. That set of conditions corresponds exactly to run number 2 in table 2 , which resulted in an adsorption capacity of $98.72 \pm 1.26 \mathrm{mg} \mathrm{g}^{-1}$, a value in good accordance with the predicted result.

Table 5 - Regression Equations of the Fitted Models in Terms of Coded Values

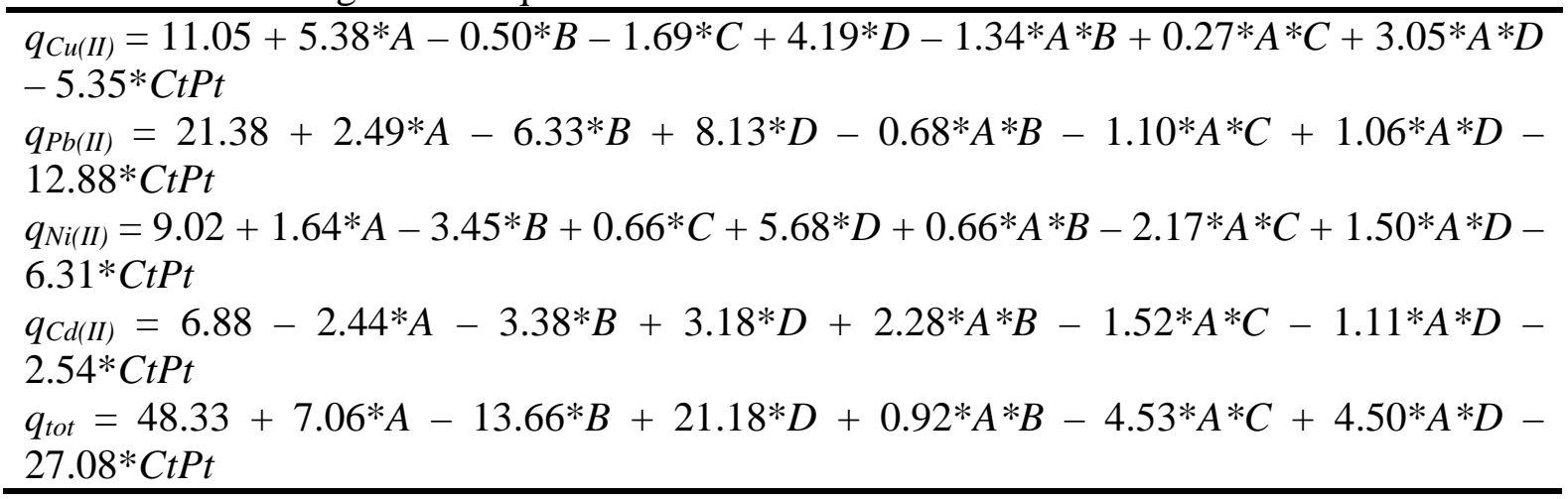

$A=\mathrm{pH} ; B=$ adsorbent mass; $C=$ agitation rate; $D=$ initial metal concentration; $C t P t=$ Central Point.

\subsection{Adsorption kinetics}

The equilibrium times found for the adsorption of metal ions onto Buriti fibers $(15 \% \mathrm{NaOH})$ were: $15 \mathrm{~min}$ for $\mathrm{Cu}^{2+}, \mathrm{Cd}^{2+}$, and 5 min for $\mathrm{Ni}^{2+}$ and $\mathrm{Pb}^{2+}$. Pseudo-first order (PFO), pseudo secondorder (PSO) and models were applied to monitor the kinetics of the adsorption process(es) and the prevailing mechanism(s). The experimental values for the adsorption capacities values $\left(\mathrm{q}_{\mathrm{e}}\right)$ were found to be in agreement with those of the theoretical adsorption capacities $\left(\mathrm{q}_{\mathrm{c}}\right)$ that were calculated by the PSO model as supported by the $\mathrm{R}^{2}$ values and error functions(not shown). Results were also adjusted the diffusion models of weber Morris ${ }^{22}$ (not shown). However, the experimental data did not fit the model, indicating that the interaction between adsorbent and adsorbate occurs on the outer surface of the material.

\subsection{Adsorption isotherms}


Adsorption isotherms of the metal ions studied onto buriti fibers $(15 \% \mathrm{NaOH})$ were obtained by plotting the concentration of each metal ion adsorbed on the solid phase (q) versus its concentration in the liquid phase $\left(\mathrm{C}_{\mathrm{e}}\right)$ (MELO, et al. 2013). Evaluation of the experimental data by the theoretical models revealed that the Langmuir model adequately described the adsorption mechanism in a monoelement system for all metal ions studied. The adsorption capacities $\left(\mathrm{q}_{\max }\left(\mathrm{mg} \mathrm{g}^{-1}\right)\right)$ followed the order: $\mathrm{Ni}^{2+}(312.91)>\mathrm{Cd}^{2+}(202.43)>\mathrm{Pb}^{2+}(178.94)>\mathrm{Cu}^{2+}$ (175.75). For a better comparison of the binding affinities, adsorption essays were also performed in the multi-element solutions containing the same amounts of each one of the metals studied. This, for the multi-element system the adsorption capacity order was $\mathrm{Ni}>\mathrm{Cu}>\mathrm{Cd}>\mathrm{Pb}$.

\section{CONCLUSÕES}

Experimental design results showed that the factors studied influenced each metal adsorption differently. The adsorption kinetics indicated that the multi-element adsorption equilibrium was reached within $15 \mathrm{~min}$ for all metal ions studied and that the experimental data best fitted to the pseudo-second order kinetic model. The analysis of the isotherms by the non-linear model showed that the experimental data for $\mathrm{Cd}^{2+}, \mathrm{Cu}^{2+}, \mathrm{Ni}^{2+}$ and $\mathrm{Pb}^{2+}$ were best described by the Langmuir model as high $\mathrm{R}^{2}$ values. The maximum adsorption $\left(\mathrm{mg} \mathrm{g}^{-1}\right)$ capacities followed the order: $\mathrm{Ni}^{2+}(312.91)>$ $\mathrm{Cd}^{2+}(202.43)>\mathrm{Pb}^{2+}(178.94)>\mathrm{Cu}^{2+}(175.75)$.

\section{REFERÊNCIAS}

BOX, G. E.; HUNTER, W. G.; HUNTER, J. S. in Statistics for Experiments, Wiley, New York, 1978.

MELO, D. Q.; GOMES, E. C. C.; RAULINO, G. S. C.; LONGHINOTTI, E.; NASCIMENTO, R. F . Adsorption equilibria of $\mathrm{Cu}^{2+}, \mathrm{Zn}^{2+}$, and $\mathrm{Cd}^{2+}$ on EDTA-functionalized silica J. Chem. Eng. Data 2013, 58; 798-806.

MOREIRA, S. A.; SOUSA, F. W.; OLIVEIRA, A. G.; BRITO, E. S.; NASCIMENTO, R. F. Remoção de metais de solução aquosa usando bagaço de caju Quim. Nova. 2009, 32, 1717-1722.

NETO,V. O. S.; CARVALHO, T. V.; HONORATO, S. B.; GOMES, C. L.; FREITAS, F. C.; SILVA, M. A. A.; FREIRE, P. T. C.; NASCIMENTO, R. F. Coconut bagasse treated by thioureia/ammonia solution for cadmium removal: kinetics and adsorption equilibrium. Bioresources 2012, 7, 1504-1524.

SOUSA, F. W.; SILVA, M. J. B.; OLIVEIRA, I. R. N.; OLIVEIRA, A. G.; CAVALCANTE, R. M.; FECHINE, P. B. A.; SOUSA NETO, V. O.; DE KEUKELEIRE, D.; NASCIMENTO, R. F. Evaluation of a low-cost adsorbent for removal of toxic metal ions from wastewater of an electroplating factory J. Environ. Manage. 2009, 89, 1-5. 